\title{
Silenciamentos sobre gênero na historiografia brasileira: Inquisição e feitiçaria na América portuguesa
}

\author{
Marcus Vinicius Reis ${ }^{1 *}$ \\ ${ }^{1}$ Universidade Federal do Sul e Sudeste do Pará, Marabá/PA - Brasil
}

Camila Marchesan Cargnelutti $i^{* *}$

${ }^{2}$ Universidade Federal de Santa Maria, Santa Maria/RS - Brasil

\section{RESUMO}

Desde a publicação de A feiticeira, de Jules Michelet, o campo de estudos referente ao fenômeno da caça às bruxas ganhou maior evidência entre os pesquisadores e, principalmente, uma profundidade analítica marcada pela diversidade de interpretaçôes, posicionamentos e argumentos teóricos. Em contrapartida, ao tratar do contexto de renovação das pesquisas sobre a feitiçaria no Brasil, destacando, por exemplo, os "estudos sobre gênero e sexualidade [que] também imprimiu sua marca sobre o tema da feitiçaria", Laura de Mello e Souza referenciou, em 2009, somente pesquisas estrangeiras. Destacou, por exemplo, as análises de Linda C. Hults, publicadas em The Witch as Muse. Este artigo pretende, assim, problematizar a produção historiográfica brasileira acerca da feitiçaria e da religiosidade, destacando as principais vertentes, teorias e metodologias utilizadas pelos historiadores. Busca-se questionar, a partir de algumas críticas tecidas por pesquisadoras do gênero vinculadas ao tema da caça às bruxas, até que ponto a historiografia no Brasil tem se atentado para as relações de gênero como aspecto fundamental para a compreensão desse objeto de estudo.

Palavras-chave: historiografia brasileira; feitiçaria; gênero.

DOI: http://dx.doi.org/10.1590/2237-101X02104403

Artigo recebido em 23 de março de 2019 e aceito para publicação em 9 de agosto de 2019.

* Professor da Universidade Federal do Sul e Sudeste do Pará / Faculdade de História, Marabá/PA - Brasil.

E-mail: mv.historia@gmail.com. ORCID: https://orcid.org/0000-0002-5972-1289.

** Doutoranda da Universidade Federal de Santa Maria / Programa de Pós-Graduaçáo em Letras, Santa Maria/ RS - Brasil. E-mail: camila.m.cargnelutti@gmail.com. ORCID: https://orcid.org/0000-0002-0936-5124. 


\title{
Silences about gender in Brazilian historiography: Inquisition and witchcraft in Portuguese America
}

\begin{abstract}
Since the publication of Satanism and Witchcraft, by Jules Michelet, the field of Englishlanguage studies about the phenomenon of witch-hunting has gained more notice among researchers and an analytical depth marked by a diversity of interpretations, positioning and theoretical arguments that have come to include gender as an analytical tool. In contrast, new research on witchcraft in Brazil has not developed such analytical depth. For example, Laura de Mello e Souza's study about the relationship between gender and sexuality and witchcraft only references English-language research like Linda C. Huts' book The Witch as Muse. This article aims to problematize the Brazilian historiography of witchcraft and religion, highlighting the principal trends, theories and methodologies used by historians. Based on some criticisms made by gender historians related to the theme of witch-hunts, the study seeks to question the extent to which Brazilian historiography has attempted to include gender relations as an analytical tool that is fundamental to understanding witch-hunts.
\end{abstract}

Keywords: Brazilian historiography; witchcraft; gender.

\section{Silencios sobre género en la historiografía brasileña: Inquisición y hechicería en la América portuguesa}

\section{RESUMEN}

Desde la publicación de La Hechicera, de Jules Michelet, el campo de estudios referentes al fenómeno de la caza de brujas ganó mayor evidencia entre los investigadores, y principalmente, una profundidad analítica marcada por la diversidad de interpretaciones, posicionamientos y argumentos teóricos. En contraste, al tratar del contexto de renovación de las investigaciones sobre la hechicería en Brasil, destacando, por ejemplo, los "estudios sobre género y sexualidad [que] también dejó su marca sobre el tema de la hechicería”, Laura de Mello e Souza refirió, en 2009, solamente trabajos extranjeros. Destacó, por ejemplo, los análisis de Linda C. Hults, publicados en The witch as muse. Este artículo pretende, así, problematizar la producción historiográfica brasileña sobre la hechicería y la religiosidad, destacando las principales vertientes, teorías y metodologías utilizadas por los historiadores. Se busca cuestionar, a partir de algunas críticas tejidas por investigadoras de género vinculadas al tema de la caza de brujas, hasta qué punto la historiografía en Brasil ha intentado que las relaciones de género sean un aspecto fundamental para la comprensión de este objeto de estudio.

Palabras clave: historiografía brasileña; hechicería; género. 


\section{Introdução}

Ao publicar a segunda edição de seu $O$ diabo e a Terra de Santa Cruz (2009), Laura de Mello e Souza optou por redigir um novo prefácio que, em linhas gerais, buscou dar ênfase a algumas das principais obras e vertentes historiográficas que, desde 1986 - ano da primeira edição do seu livro - têm se interessado em abordar a temática da feitiçaria/bruxaria na Época Moderna. Citou, por exemplo, os trabalhos que operacionalizaram o gênero junto às discussóes em questáo, reconhecendo a "voga dos estudos sobre gênero e sexualidade [que] também imprimiu sua marca sobre o tema da feitiçaria" (MELLO E SOUZA, 2009, p. 16), referenciando a obra de Linda C. Hults, intitulada The Witch as Muse, o livro Oedipus and the Devil, de Lyndal Roper, além do trabalho intitulado Fearless Wives and Frightened Shrews, da historiadora Sigrid Brauner.

Diante dessas três referências apontadas pela autora e, conforme argumentou Michelle Perrot (2007, p. 16), sustentando o entendimento de que a escrita da história das mulheres significa "sair do silêncio em que elas estavam confinadas", cabe destacar, primeiramente, a ausência, nessa listagem da autora, de estudos realizados por pesquisadores(as) brasileiros(as) acerca desse tema e que tenham operacionalizado o gênero como categoria analítica. Diante dessa problemática, cabe, a nosso ver, realizar uma pequena provocação sobre a história das relaçôes de gênero e o modo como a historiografia brasileira acerca da feitiçaria como objeto de análise tem se posicionado frente a esse conceito: é possível afirmar que esses silenciamentos citados por Michelle Perrot permanecem entre os historiadores brasileiros quando gênero e feitiçaria são articulados?

Encontrar as razóes para essa problemática é uma tarefa subjetiva. Joana Maria Pedro (2011, p. 270), em um provocador e importante artigo, afirmou que "algumas pessoas parecem achar que as categorias 'gênero' ou 'mulheres', 'mulher', 'masculinidades', 'feminilidades', em nada contribuem para o conhecimento que constroem". Além da resistência à aplicação dessas categorias, a autora destacou que, mesmo se abandonada a "certeza da neutralidade", a "acusação de ser uma história militante" ainda prevalece como principal motivo para a resistência ao gênero no campo historiográfico brasileiro. Willem de Blécourt (2000, p. 290-291), também provocativo, perguntou se o temor dos historiadores em reconhecer a existência do patriarcado no passado tem a ver com o temor desses mesmos profissionais em reconhecer que os próprios pertencem e reproduzem essa estrutura no tempo presente. No início da década de 1990, e direcionando sua crítica para um público ainda maior, Monique Wittig (2006, p. 51) defendeu a existência de um "pensamento heterossexual", cuja função residiria em construir uma "interpretação totalizadora [e masculina] da história, da realidade social, da cultura, da linguagem e de todos os fenômenos subjetivos". Os conceitos, as análises e compreensôes dessas histórias são reduzidos a uma universalidade em que esse pensamento é dominante, sendo incapaz de conceber 
uma determinada cultura ou sociedade em geral senão por relaçóes humanas pautadas pela heterossexualidade (WITTIG, 2006, p. 52).

Caso consideradas essas interpretaçóes, poder-se-ia compreender que a temática da feitiçaria foi distanciada do gênero na medida em que não seria interesse desse sistema, ou seja, dos pesquisadores, questionar os papéis sociais de homens e mulheres, reconhecer a dominação masculina e compreender esse fenômeno para além das análises estruturantes e voltadas somente ao campo das relaçôes entre as culturas erudita e popular, ou das análises sobre as crenças e práticas presentes nos relatos. A história dos homens e, principalmente, das mulheres perseguidas a partir do fenômeno de caça às bruxas teria sido interpretada, portanto, a partir de análises preestabelecidas.

Outro ponto que merece destaque a partir dessa problemática reside no fato de que as principais referências brasileiras que, desde a década de 1980, têm se filiado à História das Mulheres ou do Gênero para analisar as relaçôes sociais na América portuguesa, não se debruçaram diretamente sobre a religiosidade ou mesmo sobre as mulheres que foram perseguidas a partir do delito da feitiçaria. Em outras palavras, é como se a História das Mulheres ou a virada do gênero na História, protagonizada, primeiramente, pelo importante artigo de Joan Scott, "Gender: a useful category of historical analysis" (1986) ${ }^{1}$, não tivesse sido operacionalizada nas estruturas interpretativas da religiosidade na América portuguesa a ponto de problematizá-las profundamente. Por outro lado, alguns campos de estudos voltados a esse mesmo espaço trataram de seguir o caminho inverso. Como um primeiro exemplo, vale mencionar o pioneiro trabalho de Mary del Priore, Ao sul do corpo (1993), que partiu da "maternidade, do parto, do corpo feminino e do cuidado com os filhos" para analisar as relaçóes sociais constituídas na América portuguesa. A autora enxergou na maternidade o principal refúgio encontrado pelas mulheres, tornando-se poderosa ferramenta de revanche diante de uma sociedade "androcêntrica e misógina" (PRIORE, 2009, p. 25). No entanto, mesmo com os avanços aqui destacados, o trabalho de Mary del Priore pecou, segundo avaliaçáo de Maria Odila Dias (1993, p. 481), pela ausência de análises profundamente críticas quanto à documentação analisada e, principalmente, pela ausência de maiores diálogos da autora com as teóricas feministas do período.

Interessada em analisar a trajetória de Chica da Silva, para além dos mitos construídos em torno de sua figura, o livro de Júnia Furtado (2003) constitui um dos principais trabalhos que, nas últimas duas décadas, se preocuparam em compreender a história das mulheres a partir das relaçóes de gênero. Percebeu, assim, como tais relaçôes, nas Minas Gerais do século XVIII, assumiram laços intrínsecos com as de raça, fazendo de Chica da Silva um dos maiores exemplos dessa interação, em que "o sexo foi determinante nas condiçóes mais ou menos facilitadas de acesso à alforria” (FURTADO, 2003, p. 109).

\footnotetext{
${ }^{1}$ No Brasil, a tradução ocorreu em 1995, através da revista Educação \& Realidade.
} 
A vida religiosa, mais precisamente aquela que se desenvolveu entre os conventos e casas religiosas existentes na América portuguesa, também se tornou, a partir da década de 1980, espaço recorrente nas análises das historiadoras, principalmente, quando do interesse em operacionalizar as ferramentas teóricas e metodológicas difundidas pela História das Mulheres e pelas teóricas do gênero. Dentre os trabalhos existentes, permanece relevante a obra de Leila Mezan Algranti que, com seu Honradas e devotas (1993), foi responsável por se tornar uma das principais referências acerca dos estudos sobre as mulheres e o universo conventual na América. Suas análises revelaram, por exemplo, as grandes rupturas para com o ambiente ortodoxo que foram protagonizadas de modo consciente por uma série de mulheres cujo interesse, ainda que de modo precário, residiu em reproduzir os seus modos de vida anteriores à clausura.

Diante desse breve painel historiográfico, o presente trabalho busca, portanto, dar conta da problemática levantada acerca das ausências, por parte da historiografia brasileira, de análises de gênero voltadas ao campo da religiosidade colonial, principalmente acerca da religiosidade marcada pelas práticas mágico-religiosas, mais precisamente as vinculadas às noçôes de feitiçaria e bruxaria. Também é interesse contribuir com algumas reflexóes já desenvolvidas amplamente por uma série de teóricas feministas que, acredita-se, carecem de maior análise e discussão quanto ao contexto de desenvolvimento dos estudos voltados à temática da feitiçaria para a América portuguesa. Sendo assim, as análises que serão desenvolvidas ao longo dessas páginas têm por interesse refletir acerca da historiografia brasileira que se debruçou sobre a religiosidade nesse espaço, mais especificamente, sobre os estudos referentes às práticas mágico-religiosas. Dessa forma, nesse estudo será construído um painel geral dessa produção, desde o lançamento da já mencionada obra de Laura de Mello e Souza, visando refletir sobre os motivos para que os estudos de gênero não tenham avançado nesse campo, ainda mais se comparados com outras temáticas relacionadas a essa época e que têm sido abordadas pelos(as) pesquisadores(as) brasileiros(as).

\section{A emergência e o desenvolvimento dos estudos sobre a religiosidade no Brasil}

Não é repetitivo destacar o caráter de ineditismo e inovação adquirido por $O$ diabo e a Terra de Santa Cruz num contexto em que os estudos no Brasil a respeito da religiosidade ainda estavam em segundo plano no âmbito da produção historiográfica. Conforme sublinharam Ronaldo Vainfas e Ciro Cardoso (1997, p. 82), ao abordarem a emergência da História das Mentalidades e dos estudos culturalistas entre os historiadores, as décadas de 1960 e 1970 foram decisivas para a consolidação e hegemonia dos métodos quantitativos para as análises referentes às fontes históricas. Para os autores, é a partir da "crise dos estruturalismos", ou seja, quando avançaram os questionamentos sobre as análises braudelianas, marxistas e fun- 
cionalistas no decorrer das duas décadas seguintes, que os historiadores passaram a defender o pressuposto de que as realidades sociais náo deveriam ser analisadas a partir de modelos preestabelecidos. Nas palavras de Roger Chartier (2002, p. 8), ao terem refletido sobre o contexto da historiografia europeia a partir da década de 1980, essas novas problemáticas representaram a fragmentação das principais tradiçôes historiográficas vigentes até então, dando origem à multiplicidade dos objetos, dos métodos e das abordagens, bem como das histórias. Não foi mera coincidência, portanto, que os trabalhos sobre o fenômeno da caça às bruxas tenham adquirido fôlego a partir dessa época, tanto na Europa, como no Brasil.

Logicamente, e para o contexto historiográfico brasileiro, vale destacar os esforços de análises empreendidos por Gilberto Freyre e Sérgio Buarque de Holanda, principalmente em Casa-grande \& Senzala (2006) e Visão do paraíso (1994) - originalmente publicadas em 1933 e 1959, respectivamente - e que permanecem como obras fundamentais para a compreensão da religiosidade na América portuguesa. De todo modo, não é exagero afirmar que, para o âmbito brasileiro, a publicação, em 1986, de O diabo e a Terra de Santa Cruz marcou sensivelmente os estudos sobre a religiosidade no mundo luso-brasileiro. Esse livro significou um notável esforço de Laura de Mello e Souza em articular a historiografia europeia clássica ao tema com as suas análises sobre as mais variadas formas como a América portuguesa construiu seu acesso ao sobrenatural. Destaca-se, também, a extensão da documentação utilizada pela autora, bem como a sua diversidade: processos inquisitoriais, devassas eclesiásticas, documentação jurídica e tratadística, principalmente as de cunho religioso.

Com a publicação de Inferno atlântico, em 1993, Laura de Mello e Souza foi influenciada diretamente pela chegada das obras de Carlo Ginzburg ${ }^{2}$ ao Brasil e pela emergência de estudos baseados na microstoria italiana. Ginzburg chamou a atenção para a importância do pesquisador não se preocupar apenas em analisar a existência do pacto diabólico, já que a escolha por esse caminho privilegiaria somente a cronologia de feitura do próprio processo. Seguir essa vertente significaria corroborar as versóes construídas pelos próprios inquisidores, revelando apenas um lado da cultura popular, pois esses, não raro, a interpretaram de forma negativa e de modo superficial. Por isso o seu interesse em reconstruir as crenças, buscando repensar as interpretaçóes enviesadas formuladas pelos pesquisadores, alargando o recorte temporal da sua análise, a fim de perceber as influências culturais, as persistências ou mesmo as rupturas em relação às crenças narradas pelos indivíduos, além dos relatos moldados pelos inquisidores (GINZBURG, 1991, p. 30).

Conforme destacado em trabalho anterior (REIS, 2019), boa parte dos debates empreendidos por Laura de Mello e Souza nesse segundo livro relacionaram uma escala de

\footnotetext{
${ }^{2}$ Especialmente em Os andarilhos do bem (1988) e História noturna (1991), Carlo Ginzburg inovou os estudos referentes à feitiçaria/bruxaria, a partir do século XVI, num contexto italiano e sob uma perspectiva micro-histórica.
} 
observação mais reduzida - por vezes se utilizando de trajetórias individuais a partir dos processos do Santo Ofício português - junto a uma ótica estrutural para compreender, por exemplo, os possíveis significados que o mito do sabá assumiu no imaginário "luso-brasileiro do Antigo Regime" (MELLO E SOUZA, 1993, p. 161)³. O mito em questão, e que se tornou alvo de suas discussões no último capítulo desse trabalho, não seguiu os mesmos contornos da tradição demonológica europeia vigente à época, muito por conta de dois elementos fundamentais sublinhados pela autora: a própria especificidade dessa tradição no território português e a convivência com práticas mágico-religiosas ameríndias que alimentaram esse imaginário específico em torno do diabo no Novo Mundo.

Publicado em 1988, O sexo proibido, de Luiz Mott, é considerado pelo autor como a "primeira tentativa de sistematização dos documentos relativos aos crimes sexuais e heresias morais perseguidos pelo Santo Ofício em Portugal e no Brasil” (p. 12). Diante desse trabalho de reunião de fontes atrelado ao objetivo de investigar os mecanismos de repressão utilizados pelo Santo Ofício no domínio da sexualidade, o autor percorreu o universo das práticas sexuais entre os africanos num primeiro momento, partindo, em seguida, para o universo homossexual na América portuguesa - "pecado que os inquisidores consideravam táo feio, sujo e desonesto, que até o diabo fugia quando o via ser praticado" (MOTT, 1988, p. 14). Por fim, o autor se debruçou no debate em torno da virgindade de Nossa Senhora, "um dos mitos mais sagrados e polêmicos do catolicismo".

Defendida em 2000 no Programa de Pós-Graduação em História da Universidade Federal Fluminense, a tese de Daniela Calainho, intitulada Metrópole das mandingas, deu origem a um livro publicado em 2008, com o título homônimo. Ao tratar das bolsas de mandinga e sua circulação no Império português, a autora afirmou que o termo "mandinga" remonta ao passado islâmico na África, por volta do século VII, com a expansão árabe nesse continente e que se desenrolou até o século XIII. Foi nesse período, por conta da conversão dos malinkê, pertencentes ao Reino Mali, ao islamismo, que as bolsas de mandinga começaram a circular, tornando-se sinônimos de amuletos e patuás utilizados pelos mandingas. No entender da autora, esses objetos são exemplos de um "sincretismo muçulmano-fetichista" que foram espalhados para além das fronteiras africanas (CALAINHO, 2008, p. 173-174).

Ao analisar os processos do Santo Ofício português contra os indivíduos acusados de portarem esses amuletos, a autora percebeu uma intensa circularidade de rituais e de crenças a partir da presença dessas bolsas entre os negros residentes em Portugal, sendo amplamente utilizadas pela sociedade lusitana, responsável pelas crenças na eficácia simbólica dessas bolsas. Seu trabalho permanece, assim, entre as principais obras que apresentam uma notável maturidade referente às análises sobre as práticas mágico-religiosas no mundo português. Destaca-se, também, a sofisticaçáo das suas discussóes quando da aplicação dos conceitos utilizados por Carlo Ginzburg. Cabe igualmente sublinhar a ampliaçáo da perspectiva de

\footnotetext{
${ }^{3}$ Ou seja, cerimônias coletivas de pacto com os diabos.
} 
análise, na qual a autora se voltou ao "complexo cultural híbrido envolvendo a África e o Brasil" e os diálogos empreendidos com Portugal.

Defendida em 2008 na Universidade de São Paulo, a tese de doutorado de Vanicléia Silva Santos, As bolsas de mandinga no espaço Atlântico, embora tenha partido do mesmo recorte temático desenvolvido por Daniela Calainho, trouxe importantes inovaçôes para o campo de estudos da religiosidade negra no Brasil. A primeira delas consistiu na importância conferida pela autora ao modo como a religião seria entendida no seu trabalho, compreendendo-a a partir "da continuidade das tradiçóes africanas sob a perspectiva da 'interpenetração cultural' e/ou criação de novas instituiçóes no Novo Mundo" (SANTOS, 2008, p. 17).

Seguindo a linha interpretativa utilizada por Laura de Mello e Souza, o trabalho de Carolina Rocha, O sabá do sertão (2015), é um dos mais recentes estudos publicados no Brasil, partindo da documentação inquisitorial para compreender as relaçôes empreendidas pelas mulheres para com a figura do diabo. Seu recorte cronológico abarca os anos de 1750 a 1758, e o espacial a autora denominou de "Piauí Colonial". Suas análises estão concentradas nas confissóes de Joana Pereira de Abreu e de Custódia de Abreu, ambas registradas pelo jesuíta Manuel da Silva e pertencentes aos Cadernos do Promotor, nas quais a autora identificou as práticas mágico-religiosas sob uma dupla ótica, voltando-se para os colonizadores e para os colonos, entendendo-as como uma função social. Entre os primeiros, tais práticas justificaram a evangelização e o avanço das políticas de expansão portuguesa, já que encarnavam a "influência do diabo sob aqueles povos". Entre os últimos, percebeu uma gama maior no recurso ao sobrenatural, pois permitia o "alívio das tensôes inerentes do sistema escravista, da miséria, das angústias e incertezas, dos desamores e desafetos, das pulsóes sexuais, das doenças, e de todos os sentimentos ligados ao seu inconsciente e à sua condição social” (ROCHA, 2015, p. 237).

O olhar mais aproximado a respeito das análises e reflexóes realizadas por esses(as) autores(as) permite identificar que os seus trabalhos, de fato, se preocuparam em detectar o número de indivíduos processados pelo delito da feitiçaria, além de terem destacado a presença dos homens e das mulheres nesse contexto de acusação. No entanto, pode-se também afirmar que essa identificação não avançou de modo mais aprofundado a ponto desses mesmos pesquisadores terem se preocupado em construir maiores discussóes sobre os motivos para que as mulheres tenham sido amplamente associadas ao sobrenatural, incluindo aí uma percepção negativa. Considerando as críticas de Anne Barstow (1988, p. 12), os trabalhos referenciados acima integram um contexto de interpretaçóes por parte dos historiadores cujo fenômeno de "caça às bruxas" não foi analisado a partir das questóes de gênerót. Se compa-

\footnotetext{
${ }^{4}$ Conforme destacou a autora, a maioria dos estudiosos voltados ao fenômeno da "caça às bruxas" negligenciou o fato de que as vítimas, em sua maioria mulheres, possuíam uma identidade, encarando-as somente como objetos sexuais.
} 
rados aos trabalhos desenvolvidos por historiadores estrangeiros nas últimas décadas acerca da religiosidade no mundo português e como esta esteve vinculada à crença no diabo e às relaçôes de gênero estabelecidas nesse espaço, percebemos como esse hiato é uma característica recorrente da historiografia brasileira.

Assim, a maioria dos estudos aqui destacados não se concentraram em compreender quais foram os papéis sociais das mulheres e dos homens nesse período e como elas e eles foram alvo de normatizaçóes e ressignificaçôes por parte dos indivíduos a partir do interesse no acesso ao sobrenatural através das práticas mágico-religiosas. Sendo assim, defendemos que o "gênero formou cada aspecto da feitiçaria na Época Moderna e dos julgamentos contra as feiticeiras" (ROWLANDS, 2003), percorrendo desde a formação das identidades de gênero das mulheres feiticeiras às tensóes decorrentes dos mecanismos punitivos e da atmosfera patriarcal e misógina existente à época.

\section{A virada do gênero e os estudos sobre o fenômeno de caça às bruxas}

Já é argumento consolidado entre as teóricas feministas, como Joan Scott (1995, p. 6465), que a emergência da História das Mulheres está diretamente relacionada ao campo da política, principalmente a política feminista que, a partir da década de 1960, ganhou força e amplitude nos mais diversos espaços públicos, resultando na maior capacidade de mobilização e mudança no universo das relaçôes de poder entre homens e mulheres. Cabe ressaltar a considerável importância dos estudos realizados por Virginia Woolf ${ }^{5}$, Simone de Beauvoir ${ }^{6}$ e, posteriormente, pelas análises desenvolvidas por Michele Perrot ${ }^{7}$, pois se tornaram importantes contribuiçôes para que essa disciplina se consolidasse ao longo do século XX.

Com o avançar da década de 1980, tomou forma, entre algumas teóricas, o interesse em defender e aprofundar o que Margareth Rago (2012, p. 50) definiu como a "construçáo social e cultural das diferenças sexuais". Tais estudos foram influenciados por uma literatura que buscou valorizar as discussóes sobre o novo papel dos sujeitos, a necessidade de desnaturalizar as identidades, bem como os conceitos que sustentavam a vida social, cultural e política. Em

\footnotetext{
${ }^{5}$ Uma das principais obras de Virginia Woolf é Um quarto que seja seu (1978, p. 65), publicado originalmente em 1929, no qual buscou questionar os papéis que as mulheres adquiriam ao longo da história.

${ }^{6}$ Talvez a frase mais célebre de Simone de Beauvoir, retirada do seu livro $O$ segundo sexo, seja a de que "ninguém nasce mulher: torna-se mulher" (2016, p. 11). Ainda que tenha apontado as limitaçóes referentes ao trabalho de Beauvoir, como o fato da autora ter subestimado o falocentrismo, Judith Butler não desconsidera a frase citada, afirmando que "se há algo de certo na afirmação de Beauvoir [...] decorre que mulher é um termo em processo, um devir, um construir de que não se pode dizer com acerto que tenha uma origem ou um fim" (BUTLER, 2003, p. 58-59).

${ }^{7}$ Uma das principais pesquisadoras referentes a esse campo de pesquisa, Perrot contribuiu decisivamente para que essa disciplina tenha avançado no âmbito acadêmico francês a partir da década de 1970. Em 1984, por exemplo, publicou uma de suas principais obras, Une histoire de femmes, est-elle possible?
} 
Problemas de gênero, por exemplo, a filósofa Judith Butler tratou de defender uma genealogia das noçôes de sexo, desejo e gênero, reconhecendo que as ideias de "feminino" e "mulher" não são simples categorias estáveis. Afirmou, ao dialogar com Simone de Beauvoir, que, "se alguém 'é' uma mulher, isso certamente não é tudo o que esse alguém é", tendo em vista que os gêneros não são performatizados de modo alheio aos contextos históricos, tampouco estão desvinculados de outras modalidades, como as raciais, classistas, culturais, que incidem diretamente no modo como são produzidos ao longo do tempo (BUTLER, 2003, p. 20).

Logicamente que as discussões teóricas acerca do gênero extrapolam o espaço de reflexôes proposto por este artigo, uma vez que os debates permanecem na contemporaneidade e não assumem uma única vertente. Além do mais, é interesse deste trabalho compreender como algumas pesquisadoras, principalmente, operacionalizaram esse conceito a partir do interesse em analisar o fenômeno ocidental da caça às bruxas. Por essas razóes, as reflexôes a seguir partem dos trabalhos mais recentes que buscaram utilizar o gênero a partir das práticas e crenças que sustentaram esse fenômeno ao longo da Época Moderna ${ }^{8}$.

Há mais de três décadas tem prevalecido na historiografia referente a esse tema um esquema interpretativo que busca identificar e valorizar as relaçôes de poder entre inquisidores e acusados como aspecto essencial no contexto das arguiçóes e do desenvolvimento da atmosfera demonológica. A principal justificativa reside no fato de que é nesse contexto que são produzidos "testemunhos hostis, que provêm de demonólogos, inquisidores e juízes ou foram por eles filtrados" (GINZBURG, 1991, p. 21). Carlo Ginzburg identificou essa problemática entre os benandanti, após ter analisado as inúmeras arguiçôes realizadas pelos inquisidores no Friul: "se tornam, como veremos, feiticeiros; e suas reuniōes noturnas, que têm como objetivo proporcionar fertilidade, transformam-se no sabá diabólico, com a sua seqüela de tempestades e destruiçôes" (GINZBURG, 1988, p. 11). Se compartilhado esse entendimento, será possível "captar, por trás da aparente uniformidade dessas crenças, as diversas atitudes dos homens e das mulheres que as viviam, bem como a modificação delas sob o impulso de estímulos de vários gêneros, tanto populares quanto inquisitoriais" (p. 12).

No entanto, acredita-se que as análises de Ginzburg - que, aliás, influenciaram uma série de trabalhos no Brasil referentes ao tema, como os já citados livros de Laura de Mello e Souza e Daniela Calainho - não tenham abordado a problemática referente à construção do

\footnotetext{
${ }^{8}$ É importante destacar que a História não é o único campo de conhecimento que, através dos seus pesquisadores, se interessou em analisar as relaçóes entre gênero e a feitiçaria. Andrew Apter (2018), por exemplo, possui uma produção considerável acerca da religiosidade negra, analisando-a a partir da interação entre uma perspectiva histórica e antropológica. Entre as historiadoras que buscaram avançar na articulação entre História e outras áreas de conhecimento a fim de compreender o fenômeno de caça às bruxas, destaca-se o trabalho de Lyndal Roper, Oedipus and the Devil (2005). Ao destacar a importância do gênero como um "produto da prática cultural e linguística", a autora também defendeu a realidade subjetiva como aspecto essencial para a compreensão desse fenômeno, em que a psicanálise aparece como ferramenta primordial nas suas discussões, uma vez que a formação das identidades abrangeu o inconsciente e o modo como homens e mulheres entenderam os seus papéis sociais e a sua sexualidade.
} 
binômio mulheres/diabo. Pode-se justificar essa questão tendo em vista os próprios objetivos do autor. Em História noturna, por exemplo, suas reflexôes pretenderam "reconhecer uma 'formação cultural de compromisso': resultado híbrido de um conflito entre cultura folclórica e cultura erudita" (GINZBURG, 1991, p. 22). Segundo Elspeth Whitney (1995, p. 82), mesmo tendo defendido e valorizado enfaticamente a importância de os historiadores enfocarem a relação entre perseguidores e perseguidos, inserindo-a no centro das suas investigaçôes, Carlo Ginzburg "surpreendentemente mostrou pouco interesse em explorar questôes de gênero". Faltou, portanto, compreender o peso das relaçôes de gênero e a possibilidade de a feitiçaria ter se tornado um conceito generificado ou, segundo Michael Bailey (2002, p. 130), uma "forma mais feminizada da magia realizada pelas elites".

Pode-se dizer que a historiografia internacional, tanto norte-americana como europeia, tem se atentado desde o início da década de 1990 para a necessidade de os pesquisadores problematizarem as estruturas de poder, bem como as interpretaçôes clássicas acerca do fenômeno de caça às bruxas, muito por conta dessas análises não terem avançado para além da superfície das relaçôes entre os indivíduos acusados de se comunicarem com os diabos e os mecanismos de perseguição. Entre as primeiras pesquisas que trataram de evidenciar essa problemática, estão as desenvolvidas pela historiadora Anne Barstow.

Em um artigo publicado em 1988, no Journal of Feminist Studies in Religion, intitulado "On studying witchcraft as Women's Story. Historiography of the European witch persecutions", o principal questionamento de Anne Barstow acerca dos estudos sobre a caça às bruxas esteve direcionado à ausência de interpretaçôes que considerassem as questóes de gênero como elemento essencial para a compreensão desse fenômeno. Criticou, assim, o clássico artigo de Hugh Trevor-Hoper - "A mania europeia de bruxas nos séculos XVI e XVII". Segundo a autora, embora tenha conferido maior peso à presença das mulheres como fator importante para a compreensão desse fenômeno como uma perseguição aos grupos marginalizados, Trevor-Roper não fugiu das interpretaçôes mais gerais que entendiam essas mulheres como indivíduos histéricos ou sexualmente devassos. Em trabalho posterior, a autora defendeu a importância de o pesquisador náo apenas problematizar a relaçáo entre a sexualidade das mulheres e as práticas interpretadas sob o conceito de "bruxaria", mas, principalmente, entender como elas construíram e vivenciaram as suas sexualidades na Época Moderna, sem que sejam estabelecidos juízos de valor (BARSTOW, 1999, p. 178).

Além dessas consideraçóes levantadas por Anne Barstow, também foi sublinhado pela autora o fato de que uma série de interpretaçóes e motivos foram levantados pelos historiadores a fim de justificarem não apenas esse fenômeno, mas a amplitude das perseguiçôes direcionadas às mulheres. E o principal embasamento dessas análises residiu nos argumen-

\footnotetext{
${ }^{9}$ Tanto é que a misoginia aparece na obra de Ginzburg como forma de destacar a recusa às explicaçóes que aplicaram esse conceito: "explicar tal fenômeno com a misoginia dos inquisidores seria simplista; explicá-lo por meio de uma misoginia difusa, perceptível já nos testemunhos e nas denúncias, significaria cair numa tautologia” (GINZBURG, 1991, p. 302).
} 
tos de Christina Larner, socióloga escocesa e autora de Witchcraft and Religion: "as razóes pelas quais as bruxas foram caçadas não estão relacionadas com o fato de serem mulheres diretamente, mas com o fato de serem consideradas más" (BARSTOW, 1988, p. 17). Entretanto, continua Barstow, o maior equívoco desses estudos residiu na displicência acerca das análises sobre os conceitos de sexo e gênero. Primeiramente, por conta de os historiadores terem tratado as mulheres acusadas de feitiçaria/bruxaria como meros objetos sexuais. Além disso, negligenciaram o fato de que os padróes de feminilidade prescritos a elas nesse período "moldaram a forma como elas eram vistas". A ausência do patriarcado como categoria analítica também impossibilitou que essas pesquisas compreendessem como as sociedades estão alicerçadas em relaçóes de poder generificadas (BARSTOW, 1988, p. 18). Sendo assim, somente quando os historiadores da bruxaria/feitiçaria se atentarem para a necessidade de distinguir os papéis de gênero da sexualidade, que serão mais profícuas as avaliaçôes sobre os motivos de as mulheres terem sido maiormente encaradas como ameaça e terem delimitado as suas identidades de gênero a partir das práticas mágico-religiosas.

Sete anos após os diagnósticos apresentados por Anne Barstow, e com o avanço dos estudos de gênero, a também historiadora Elspeth Whitney ingressou no contexto de discussões sobre a utilizaçâo desse conceito junto ao fenômeno em questão. A maturidade não somente das discussóes acerca do gênero, mas, também, as formas encontradas pelos pesquisadores para a sua aplicação, também merece destaque - vide a preocupação da autora em clarificar que essas abordagens não pressupóem caracterizar a "caça às bruxas" como uma simples "caça às mulheres". Além disso, a autora não se furtou em endossar o mesmo posicionamento de Anne Barstow e apontar os equívocos dos historiadores que negligenciaram o gênero como categoria fundamental, questionando, assim, as proposiçóes de Christina Larner: "Larner, tendo levantado a questão de saber se a caça às bruxas era a caça às mulheres, conclui que não era, mas não explora as ligaçôes entre gênero, poder e autoridade política" (WHITNEY, 1995, p. 80) $)^{10}$.

Para Elspeth Whitney, é inviável descolar a figura da bruxa da sexualidade e dos papéis de gênero na medida em que, a partir dos séculos XVI e XVII, as mulheres se tornaram "uma nova fonte potente de ansiedade social", motivada pelo peso cada vez maior da influência e do controle masculino nas decisóes políticas atreladas às Reformas religiosas - Protestante e Católica. Concluiu, por fim, que, diante da variedade de práticas e atividades antes consideradas privadas e exclusivas das mulheres - como as parteiras e as curadoras - e, com o avançar desse controle, elas adquiriram o maior "interesse público e as fontes de autonomia das mulheres tanto dentro da cultura popular quanto dentro da própria família, foram cada vez mais truncadas e tornadas suspeitas" (WHITNEY, 1995, p. 89). Sendo assim, a

\footnotetext{
${ }^{10}$ Alison Rowlands (2003, p. 453), por sua vez, questionou o peso conferido pelos historiadores às consideraçôes de Christina Larner, muito por conta do que teria sido uma interpretação enviesada dos mesmos acerca dos pressupostos da socióloga.
} 
formatação de um padrão de feminilidade progressivamente normativo e restritivo é capaz de explicar o maior número de mulheres acusadas de serem feiticeiras.

Publicado em 1995, o trabalho de Diane Purkiss, intitulado Women's Stories of Witchcraft in Early Modern England, defendeu que a aplicação do gênero não pressupõe identificar somente uma narrativa misógina capaz de explicar a relação destacada - assim como uma série de historiadores realizavam em suas narrativas. Trata-se de compreender o peso adquirido pelas relaçôes de gênero e dos padrôes de masculinidade e feminilidade na consolidação de uma crescente atmosfera de receios e medos sobre as mulheres que foram encarnados na noção de feitiçaria ${ }^{11}$.

Embora tenha criticado a historiografia feminista referente ao tema por conta da sua constante negligência às pesquisas arquivísticas, Willem de Blécourt (2000, p. 291) destacou a importância desse campo de estudos para a ressignificação das interpretaçôes sobre o fenômeno de caça às bruxas. Tanto é que a sua principal crítica recaiu nos historiadores cujos trabalhos negaram a importância do gênero e do patriarcado nesse contexto. Sendo assim, operacionalizar esse conceito implica, primeiramente, em problematizar as grandes estruturas de dominação, além de sustentar que esse fenômeno não consistiu apenas em uma caça às mulheres. Trata-se de aprofundar as explicaçóes referentes ao amplo número de mulheres que foram relacionadas ao sobrenatural e, em dado momento, aos aspectos negativos dessa relação: o pacto diabólico. Por outro lado, o ato de questionar os motivos para a predominância de mulheres pertencentes não apenas ao quadro de acusaçôes referentes à feitiçaria ou interessadas em contar com as mulheres feiticeiras, mas, também, entre os números totais de denunciantes acerca dessas mesmas feiticeiras, é uma prática ainda pouco recorrente na historiografia brasileira.

\section{O gênero silenciado na historiografia brasileira sobre a feitiçaria}

Por mais que sejam necessárias algumas críticas acerca das obras de Laura de Mello e Souza, estas serão pontuadas de modo coerente ao seu contexto de publicaçáo. Talvez uma das maiores problemáticas referentes às suas análises, em que pese o grande volume de documentação utilizada, seja a dificuldade em avaliarmos quais foram as reais contribuiçóes das dinâmicas individuais na formatação da religiosidade na América portuguesa. Sabemos mais das crenças e práticas realizadas nesse espaço e como estáo integradas no processo de formação do chamado "Sistema Colonial" do que sobre os indivíduos responsáveis por essa multifacetada religiosidade.

\footnotetext{
11 "Abandonar as simplificadas narrativas globais da misoginia em favor de um relato mais detalhado das histórias das mulheres não torna a questão do gênero irrelevante; coloca essa questáo de uma forma nova e urgente. Para ler as histórias produzidas pelas mulheres [é necessário] fazer novas perguntas sobre o papel desempenhado pela ideologia de gênero no despertar das ansiedades e medos sobre as mulheres" (PURKISS, 1995, p. 409).
} 
Seu livro, O diabo e a Terra de Santa Cruz, pertence, claro, a um contexto de reorientação das pesquisas históricas no Brasil, cujo interesse residia em ampliar os objetos de análise, as abordagens teóricas e de valorização das grandes estruturas na longa duração. Assim, é possível visualizar nesse trabalho um esforço visível de reflexão pertencente ao âmbito da História das Mentalidades, mais do que o interesse da autora em dialogar com a História das Mulheres, por mais que esta também estivesse em voga no período. Tanto é que, em um breve comentário acerca do trabalho de Laura de Mello e Souza, a historiadora Margareth Rago (1995, p. 83) classificou essa obra como representante de uma História das Mentalidades e não de uma História das Mulheres ou das relaçóes de gênero. O mesmo vale para as primeiras impressóes dos historiadores quanto à publicação desse livro. Em 1988, Ronaldo Vainfas (1988, p. 167) classificou as análises da autora como "uma das mais notáveis incursôes de nossa historiografia no campo das mentalidades [...] marcando decisivamente os estudos da história das mentalidades no Brasil".

Por sua vez, a mesma crítica de Elspeth Whitney às análises de Carlo Ginzburg, principalmente pela negligência ao gênero como conceito capaz de aprofundar as reflexôes sobre as culturas híbridas, também é aplicável ao trabalho de Daniela Calainho. A autora, por exemplo, não possuiu, no decorrer de Metrópole das mandingas, uma preocupação visível em discutir a possibilidade das práticas mágico-religiosas dos negros e mulatos, bem como a perseguição inquisitorial, terem sido generificadas. Tendo em vista o número majoritário de homens negros e mulatos que foram processados e denunciados pela Inquisição portuguesa entre os séculos XV a XVIII - dos 93 processos realizados contra indivíduos negros e mulatos, 55 processos foram contra homens -, a operacionalização do gênero seria ainda mais produtiva. Em outras palavras, ainda que a presença majoritária de homens no âmbito das acusaçóes de feitiçaria possa contradizer os argumentos referentes à maior relação das mulheres com o sobrenatural, os dados levantados pela autora são coerentes ao fato de que o gênero deve ser operacionalizado de modo relacional. Homens e mulheres construíram suas identidades e estabeleceram relaçôes sociais de modo intimamente vinculado às relaçôes de poder, nas quais ambos estiveram inseridos de forma relacional em meio às "complexas conexôes entre as várias formas de interação humana" (SCOTT, 1995, p. 89). Isto porque, conforme sublinhou Willem de Blécourt, uma abordagem comparativa nos estudos da feitiçaria possibilitaria ao pesquisador questionar se as mulheres e os homens feiticeiros não apenas subverteram a unidade do gênero, mas os padróes de feminilidade e masculinidade a ponto de a feiticeira ter construído uma identidade masculinizada e o feiticeiro uma feminilidade própria (BLÉCOURT, 2000, p. 301).

Por seguir uma lógica parecida com a proposta 30 anos antes por Laura de Mello e Souza, o trabalho de Carolina Rocha não avança sobre as relaçôes de gênero - indício do ainda baixo número de produçôes brasileiras que articulam esse universo ao gênero, seja para o âmbito da América portuguesa, seja para um recorte mais alargado -, tampouco sobre o sentido que a 
circulação das práticas mágico-religiosas adquiriu em regiốes mais afastadas do Reino, o que, certamente, enriqueceria a obra. Seu esforço em compreender os contextos políticos do Piauí Colonial acabou por conferir pouco peso ao modo como as próprias mulheres indígenas se viam no interior dessa sociedade e em que medida esse processo passava pelo uso, ou não, de práticas voltadas ao sobrenatural. Uma importante contribuição do seu trabalho poderia residir nas relaçóes entre gênero e raça a partir da trajetória dessas mulheres indígenas.

Mariana Candido, por exemplo, tem se debruçado há alguns anos nas trajetórias das mulheres africanas, articulando os pressupostos defendidos pelos historiadores da Atlantic History ao interesse em conferir agência e protagonismo para as mulheres inseridas no contexto do mundo atlântico, mais precisamente no comércio transatlântico de escravos. Defendeu, assim, a possibilidade de os pesquisadores escreverem "uma história africana anterior ao século XX resgatando as mulheres da marginalidade e colocando-as como personagens centrais, sem cair no risco de apenas listar eventos com participação feminina e desconectados do momento histórico" (LIBERATO; CANDIDO; LOVEJOY; FRANCE, 2016, p. 224). Assim, gênero, classe e raça vêm sendo operacionalizados como conceitos recorrentes entre os africanistas, sendo uma importante saída para a compreensão do fenômeno de caça às bruxas para além do continente europeu.

Diante dos trabalhos aqui apresentados e das breves reflexóes levantadas, defende-se, enfim, a opção pelas análises que busquem valorizar as dinâmicas sociais, conforme sustentou Opitz-Belakhal, bem como as escolhas individuais realizadas pelos sujeitos diante das estruturas normativas. Como bem argumentou a autora, a reorientação das análises sobre as mulheres que foram amplamente acusadas de pactuarem com o diabo possibilitará ao pesquisador se distanciar da simples dicotomia mulheres/diabo, homens/mulheres, acusador/ acusadas, revelando, por consequência, como as relaçôes de gênero marcaram profundamente o fenômeno aqui analisado (OPITZ-BELAKHAL, 2009, p. 97). Assim, as pesquisas empíricas, como as direcionadas à documentação produzida pelo Tribunal do Santo Ofício português, poderão avaliar como as mulheres foram acusadas de se relacionarem com o diabo e de realizarem uma série de práticas mágico-religiosas, e em que medida elas interferiram na ordem natural e social defendida por Igreja e Estados. Também será possível investigar como o comportamento de algumas das mulheres foram classificados a partir da ideia de anormal, associando-a ao estereótipo negativo da feitiçaria e, "uma vez aplicado, como esse rótulo atraiu novas elaboraçóes de sua anormalidade” (BLÉCOURT, 2000, p. 308).

\section{Considerações finais}

Todas essas abordagens apresentadas, nas quais foi perceptível a dimensão conferida pelas historiadoras ao gênero para as análises acerca das práticas mágico-religiosas e do contexto de 
perseguição às mulheres feiticeiras, indicam a necessidade de os(as) pesquisadores(as) atentarem para a importância adquirida pela misoginia, não apenas no âmbito das discussóes teológicas e jurídicas. Se as diferentes formas que o patriarcado e a misoginia assumiram implicaram a produção de distintas práticas de acusação no âmbito da feitiçaria, significa afirmar que as denúncias e confissões, para além das arguiçôes dos inquisidores, estiveram arraigadas desses mesmos elementos. Assim, umas das principais potencialidades dos estudos sobre esse fenômeno, quando articuladas as análises ao conceito de gênero, reside na valorização dos testemunhos realizados, principalmente pelas mulheres, no âmbito dos inúmeros processos inquisitoriais que foram produzidos ao longo desse período, em vez de desconsiderá-los ou interpretá-los como meras reproduções dos discursos patriarcais e misóginos então vigentes.

Além disso, defendemos que, com o avanço desses pressupostos e a consciência de que as relações de gênero são capazes de explicar muito mais do que a mera relação casuística da mulher com a presença do diabo, será possível realizar uma discussão sobre como as práticas e crenças mágico-religiosas, e não somente as estruturas de perseguição protagonizadas pelas autoridades civis e religiosas, foram generificadas. Por sua vez, ao considerarmos não apenas a formação histórica brasileira, mas do próprio mundo português, a partir do comércio transatlântico de escravos, compreendendo a escravidáo como um dos principais fatores que marcaram as relaçóes sociais nesses espaços, a noção de interseccionalidade, definida originalmente por Kimberlé Crenshaw (1993), pode se tornar uma importante contribuição para os estudos de gênero vinculados à temática da feitiçaria inserida nesse contexto. Conforme salientou Joan Scott, a emergência do conceito de gênero, mais especificamente no âmbito das discussóes políticas norte-americanas, esteve atrelada ao interesse das estudiosas em teorizar a respeito da diferença sexual. Vinculadas ao cada vez mais sólido avanço dos debates identitários, as teóricas feministas destacaram a urgência em rediscutir a definição unitária e universal de mulher. Como consequência, outros conceitos como os de classe e raça adquiriram força não apenas no campo teórico, mas, também, no desenvolvimento de políticas públicas direcionadas para cada segmento (SCOTT, 1992, p. 87). Portanto, se as relaçôes de gênero produzem novas identidades da diferença, as relaçóes pertencentes à raça contribuem igualmente nesse processo, ainda mais por se tratar de um contexto em que as categorias sociais demarcaram claramente as relaçóes de poder vigentes.

Quando essas mulheres não corresponderam às expectativas de gênero existentes, ou seja, aos ideais de honra e recato, foram apontadas como indivíduos alheios às sociedades, passíveis de acusação, sendo algumas das suas identidades interpretadas a partir do delito da feitiçaria, muito por conta das crenças existentes. Ao (à) pesquisador(a), caberá a possibilidade de analisar e compreender como os padróes de feminilidade prescritos pelas estruturas de poder nesse período foram subvertidos pelas mulheres, tendo na relação ilícita com o sobrenatural uma importante ferramenta nesse processo. As análises presentes ao longo deste trabalho pretenderam, enfim, defender o entendimento de que a historiografia deve atentar 
para o modo como esses padrôes foram questionados através de várias mulheres feiticeiras mulheres que foram donas de seus corpos e de suas crenças.

\section{Referências}

APTER, Andrew. Oduduwa's Chain: locations of culture in the Yoruba-Atlantic. Chicago, University of Chicago Press, 2018.

BAILEY, Michael. The Feminization of Magic and the Emerging Idea of the Female Witch in the Late Middle Ages. Essays in Medieval Studies, v. 19, p. 120-134, 2002.

BARSTOW, Anne. On Studying Witchcraft as Women's Story. Historiography of the European Witch Persecutions. Journal of Feminist Studies in Religion, v. 4, n. 2, p. 7-19, 1988.

BARSTOW, Anne. La caza de brujas. Historia de um holocausto. Málaga: Tikal, 1999.

BEAUVOIR, Simone de. O segundo sexo. A experiência vivida. 2. v. Trad. de Sérgio Milliet. 3. ed. Rio de Janeiro: Nova Fronteira, 2016.

BLÉCOURT, Willem. Early Modern European Witchcraft. Reflections on Witchcraft and Gender in the Early Modern Period. Gender \& History, v. 12, n. 2, p. 287-309, 2000.

BUTLER, Judith. Problemas de gênero: feminismo e subversão da identidade. Trad. de Renato Aguiar. Rio de Janeiro: Civilizaçáo Brasileira, 2003.

CALAINHO, Daniela. Metrópole das mandingas: religiosidade negra e inquisição portuguesa no antigo regime. Rio de Janeiro: Garamond, 2008.

CHARTIER, Roger. À beira da falésia: a história entre incertezas e inquietude. Trad. de Patrícia Chittoni Ramos. Porto Alegre: Ed. Universidade/UFRGS, 2002.

CRENSHAW, Kimberlé. Mapping the Margins: intersectionality, identity politics, and violence against women of color, 1993. Disponível em: https://negrasoulblog.files. wordpress.com/2016/04/mapping-the-margins-intersectionality-identity-politics-andviolence-against-women-of-color-kimberle-crenshaw1.pdf. Acesso em: 29 jun. 2019.

DIAS, Maria Odila Leite da Silva. A condição feminina e suas historicidades. Revista Estudos Feministas, v. 2, n. 2, p. 481-485, 1993.

FREYRE, Gilberto. Casa-grande e senzala: formação da família brasileira sob o regime da economia patriarcal. 51. ed. São Paulo: Global, 2006.

FURTADO, Júnia Ferreira. Chica da Silva e o contratador dos diamantes. O outro lado do mito. São Paulo: Companhia das Letras, 2003.

GINZBURG, Carlo. Os andarilhos do bem. Feitiçaria e cultos agrários nos séculos XVI e XVII. São Paulo: Companhia das Letras, 1988. 
GINZBURG, Carlo. História noturna. Decifrando o Sabá. São Paulo: Companhia das Letras, 1991.

HOLANDA, Sérgio Buarque de. Visão do paraíso: os motivos edênicos no descobrimento e colonização do Brasil. 6. ed. São Paulo: Brasiliense, 1994.

MELLO E SOUZA, Laura de. Inferno atlântico: demonologia e colonização: séculos XVIXVIII. São Paulo: Companhia das Letras, 1993.

MELLO E SOUZA, Laura de. O diabo e a Terra de Santa Cruz: feitiçaria e religiosidade popular no Brasil colonial. São Paulo: Companhia das Letras, 2009.

MOTT, Luiz. O sexo proibido. Virgens, gays e escravos nas garras da Inquisiçáo, Campinas, SP: Papirus, 1988.

OPITZ-BELAKHAL, Claudia. Witchcraft Studies from the Perspective of Women's and Gender History: a report on recent research. Magic, Ritual, and Witchcraft, v. 4, n. 1, p. 9099, 2009.

PEDRO, Joana Maria. Relaçóes de gênero como categoria transversal na historiografia contemporânea. Topoi, v. 12, n. 22, p. 270-283, jan/jun. 2011.

PRIORE, Mary Del. Ao sul do corpo. Condição feminina, maternidades e mentalidades no Brasil Colônia. 2. ed. São Paulo: Editora UNESP, 2009.

PURKISS, Diane. Women's Stories of Witchcraft in Early Modern England: the house, the body, the child. Gender \& History, v. 7, n. 3, p. 408-432, nov. 1995.

REIS, Marcus Vinicius. Descendentes de Eva: práticas mágico-religiosas e relaçóes de gênero a partir da Primeira Visitaçáo do Santo Ofício à América portuguesa (1591-1595). Curitiba: CRV, 2019.

RAGO, Margareth. As mulheres na historiografia brasileira. In: SILVA, Zélia Lopes (org.). Cultura Histórica em Debate. São Paulo: UNESP, 1995.

RAGO, Margareth. Epistemologia feminista, gênero e história. Santiago de Compostela: Cnt Compostela, 2012.

ROCHA, Carolina. O sabá do sertão. Feiticeiras, demônios e jesuítas no Piauí Colonial (1750-1758). Jundiaí: Paco Editorial, 2015.

ROPER, Lyndal. Oedipus and the Devil. Witchcraft, Sexuality and Religion in Early Modern Europe. New York: Routledge, 2005.

ROWLANDS, Alison. Witchcraft and Gender in Early Modern Europe. In: LEVACK, Brian (org). The Oxford Handbook of Witchcraft in Early Modern Europe and Colonial America. Oxford: Oxford University Press, 2003.

SCOTT, Joan Wallach. Gender: a useful category of historical analysis. The American Historical Review, v. 91, n. 5 p. 1053-1075, dec. 1986.

SCOTT, Joan Wallach. Gênero: uma categoria útil de análise histórica. Educação \& 
Realidade. Porto Alegre, v. 20, n. 2, p. 71-99, jul./dez.1995.

SCOTT, Joan Wallach. História das mulheres. In: BURKE, Peter (org). A escrita da História. Novas perspectivas. Trad. de Magda Lopes. São Paulo: Editora UNESP, 1992.

VAINFAS, Ronaldo. A problemática das Mentalidades e a Inquisição no Brasil Colonial. Estudos Históricos, Rio de Janeiro. n. I, p. 167-173, 1988.

VAINFAS, Ronaldo; CARDOSO, Ciro Flamarion (orgs). Dominios da História: ensaios de teoria e metodologia. Rio de Janeiro: Campus, 1997.

SANTOS, Vanicléia Silva. As bolsas de mandinga no espaço atlântico: século XVIII. Tese (Doutorado em História) - Universidade de São Paulo, São Paulo, 2008.

WHITNEY, Elspeth. The Witch "She"/The Historian "He": Gender and the Historiography of the European Witch-Hunts. Journal of Women's History, v. 7, n. 3, p. 77-101, 1995.

WITTIG, Monique. El pensamiento herosexual y otros ensayos. Trad. de Javie Sáez y Paco Vidarte. Barcelona: Editorial Egales, 2006. 